\title{
Organizational Change Management for Sustainability in Higher Education Institutions: A Systematic Quantitative Literature Review
}

\author{
Nicola Andreij Rieg 1,*(D), Birgitta Gatersleben ${ }^{2}$ and Ian Christie ${ }^{1}$ \\ 1 Centre for Environment and Sustainability, University of Surrey, Guildford GU2 7XH, UK; \\ i.christie@surrey.ac.uk \\ 2 School of Psychology, University of Surrey, Guildford GU2 7XH, UK; b.gatersleben@surrey.ac.uk \\ * Correspondence: n.rieg@surrey.ac.uk
}

Citation: Rieg, N.A.; Gatersleben, B.; Christie, I. Organizational Change Management for Sustainability in Higher Education Institutions: A Systematic Quantitative Literature Review. Sustainability 2021, 13, 7299. https://doi.org/10.3390/su13137299

Academic Editors: Angelo Paletta and Alessandra Bonoli

Received: 31 May 2021

Accepted: 25 June 2021

Published: 29 June 2021

Publisher's Note: MDPI stays neutral with regard to jurisdictional claims in published maps and institutional affiliations.

Copyright: (C) 2021 by the authors Licensee MDPI, Basel, Switzerland. This article is an open access article distributed under the terms and conditions of the Creative Commons Attribution (CC BY) license (https:// creativecommons.org/licenses/by/ $4.0 /)$.

\begin{abstract}
Higher education institutions (HEIs) have been urged to integrate sustainability across all their structural and organizational dimensions. A promising area of research and practice that can help to deliver this is organizational change management for sustainability. While this field has received increasing attention over the past decade, a comprehensive assessment is still lacking. Therefore, a systematic quantitative review was carried out to summarize and synthesize the academic literature on organizational change management approaches that aim to holistically embed sustainability in HEIs. Furthermore, this review aims to illustrate what change factors have been observed and how they have been analyzed, and from this highlight implications for practice and pathways for future research. The literature reviewed puts strong emphasis on change processes and human factors, as well as elements of the institutional framework, such as vision and strategy. The findings highlight the value of strategic and reflective actions, the importance of understanding and actively shaping change processes, and that change towards sustainability requires broad stakeholder input and commitment. This review serves as an important reference point for future research and practice.
\end{abstract}

Keywords: university; higher education institution; sustainability; sustainable development; organizational change management; systematic review

\section{Introduction}

Higher education institutions (HEIs) are better equipped and more obliged to support and accelerate change towards sustainability than any other institution, since they can significantly contribute to education and moral engagement of future leaders and citizens [1]. Over several decades, HEIs have been urged to advance sustainable development [2-4], but implementation efforts have been characterized as sluggish, technocratic, and lacking in leadership [5,6]. Most approaches have been unsuccessful in catalyzing systemic change, since they have focused too much on individual issues such as recycling or renewable energy [7,8]. Similarly, the literature on sustainability in HEIs has been dominated by research on piecemeal approaches around operational or educational activities [9], often documenting them in a descriptive and atheoretical way [10].

Thus, more and more scholars have called for research that is methodologically rigorous, contributes to theory-building, and offers insight into approaches that aim to embed sustainability across all structural and organizational dimensions of HEIs [11,12]. Organizational change management for sustainability is an emerging field within the sustainability in higher education discourse addressing these demands [12]. Organizational change examines change context, content, and processes, with particular attention to human factors [13], and change management provides methods for moving organizations from the status quo into a more desired future state [14]. 
Although research in this field has seen increasing interest, a comprehensive assessment is lacking. Therefore, this paper adopts a systematic quantitative method to review the academic literature on organizational change management approaches that aim to holistically embed sustainability in HEIs. Contrary to narrative reviews, which focus on summarizing what is known and rely on expert judgement to sort out relevant literature, systematic quantitative reviews highlight both the known and unknown and allow for transparent rules to exclude descriptive studies and papers that limit their scope to individual issues $[15,16]$. In this way, a database of high-quality papers was compiled with the aim to determine (i) where, when, and by whom research has been conducted, and what type of research design and methods have been used; and more importantly (ii) what change factors have been observed and how they have been analyzed. The paper then discusses the change factors that research suggests are effective or promising for embedding sustainability holistically into HEIs, and the change factors that have been neglected in the current literature. It concludes by outlining implications for practice and highlighting pathways for future research.

\section{Theoretical Framework: Studying Organizational Change Management in HEIs}

Grounding the review within an organizational change management framework allows for taking a holistic view on change, considering not only the subject of change, but also how and in what contexts change happens, and the role people are playing [13]. This is important, since change towards sustainability concerns not only what is done, but also in which way it is done [17], and how stakeholders are involved [18]. Furthermore, organizational change management draws on a range of ideas, such as organizational learning or complexity theories [19]. In this way, it can provide crucial understanding of the interplay between people and organizational structures, and how they shape and are shaped by perceptions, attitudes, and behaviors [20]. Lastly, organizational change management provides tools to and clear guidance on planning and implementing change [21]. To understand characteristics and patterns of organizational change, research needs to cover context, content, process, and outcomes of change [22].

Context factors comprise the external environment of an organization, such as changes in the sector, and internal circumstances, for instance change in organizational structures [23]. While change management theory generally emphasizes internal change that is brought about by deliberate actions of change agents [24], it is important to understand context factors, as they can instigate, support, hinder, or halt change processes.

Content factors represent the subject of change, such as organizational systems or strategy [25]. In this review, content factors are divided into categories according to the seven sub-systems of HEIs as defined in Lozano et al. [12] (p. 3): institutional framework, campus operations, education, research, outreach and collaboration, on-campus experiences, and assessment and reporting. This classification is one of the most comprehensive models in the literature and allows for an in-depth and meaningful analysis. When taking a holistic approach to change, understanding content factors is paramount due to their varying degree of leverage over the organization as a whole [8].

Process factors document how change is occurring. They are divided here into three categories: type of change, such as planned or emergent; drivers and barriers; and human factors, for instance stakeholder perceptions and behaviors. Process factors influence one another and other change factors in a myriad of ways, and understanding them is crucial not only for integrating sustainability in HEIs [9], but also to better differentiate, compare, and replicate change patterns across different HEIs [26].

This review does not cover outcome factors, since isolating particular outcome variables in a controlled way is extremely difficult when examining change at the organizational level. Instead, leadership was added as fourth overarching theme. Leadership factors are closely intertwined with organizational change [27] and usually describe who exerts leadership and their leadership style. The latter is particularly important, since leadership for sustainability has a range of moral and ethical implications $[28,29]$. To reflect the distributed 
organizational structure of HEIs with their peculiar power and authority systems [30], leadership factors are classified here into top-down, led by senior staff; bottom-up, driven by students; and middle-out, headed by faculty and admin staff [31]. A fourth category is change leadership, which looks at the more generic discourse around the different types of leadership in HEIs.

The four overarching themes and their categories depicted in Figure 1 acted as guiding points when determining inclusion and exclusion criteria as well as structuring and analyzing the review database. The framework also served as a cornerstone for illustrating the findings and helped to identify constellations of change factors that research suggests are effective for embedding sustainability into HEIs, and areas where more research might be needed. While the overarching themes and their change factors are closely connected, it is beyond the scope of this review to detail how they influence each other, as a different method would be needed (e.g., [26,32]).

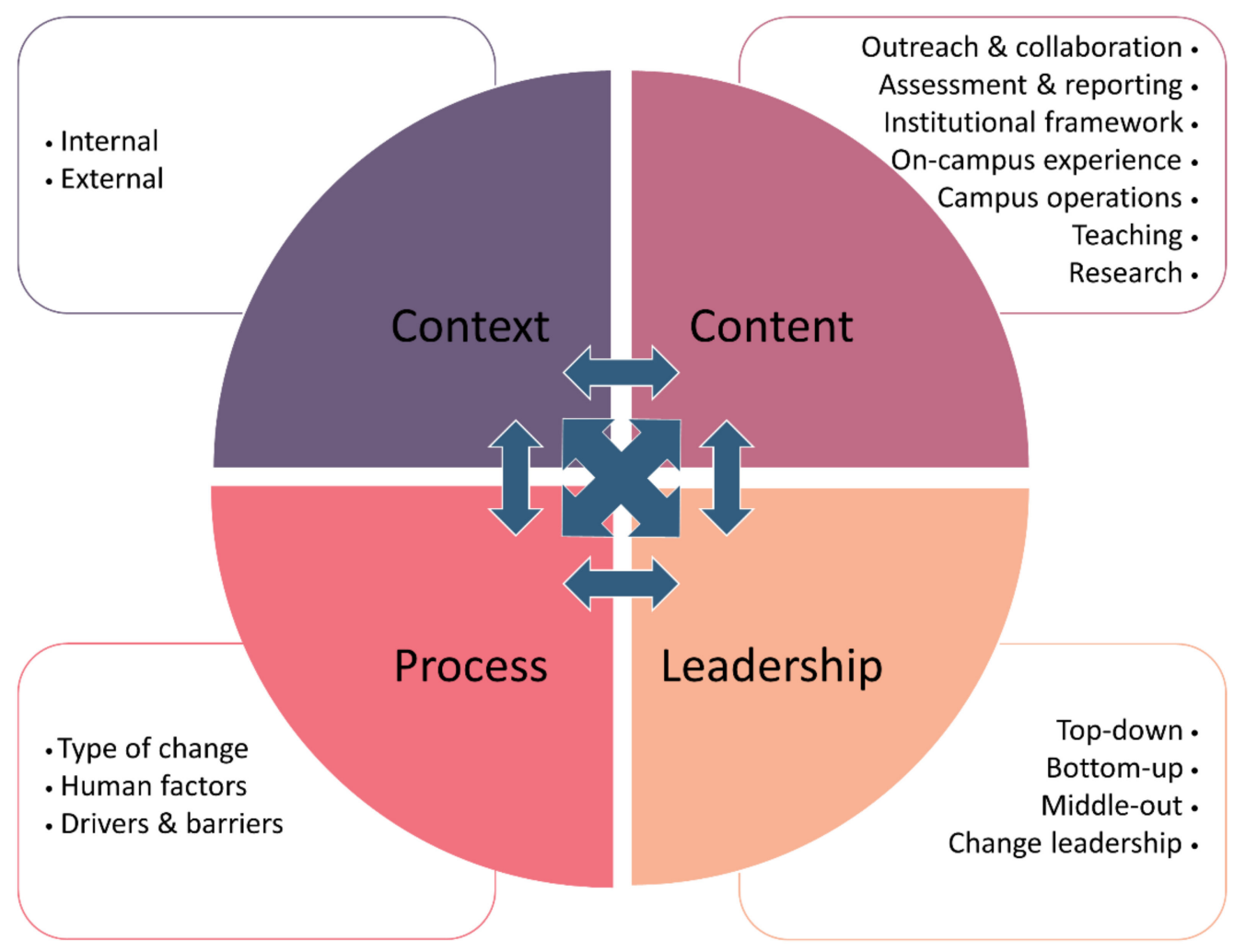

Figure 1. Theoretical framework for the systematic literature review on organizational change management for sustainability in HEIs.

\section{Methods}

This review followed an approach consistent with the systematic quantitative assessment technique outlined by Pickering and Byrne [33]. Their review method is divided into two phases and ten steps: the first phase lays the foundation for the review through defining the topic (1), research aims and questions (2), identifying keywords (3), selecting, and searching databases (4), and reading and assessing publications (5). In the second phase, the database is structured (6), and $10 \%$ of eligible publications are entered (7). In this way, the categories of the database can be tested and revised (8). The remaining publications are then entered (9) and analyzed (10).

The method of Pickering and Byrne [33] has been found to be the most appropriate for this review. Contrary to systematic reviews for weighting and meta-analysis which usually address narrowly defined research questions and focus on specific types of literature [34], the systematic quantitative technique allows for reviewing emerging and interdisciplinary 
fields and areas of methodological diversity (e.g., [35,36]). This makes it particularly wellsuited for reviewing the research on organizational change management for sustainability in HEIs. To ensure transparency and reproducibility, in the following, each of the ten steps taken is introduced and explained.

After an initial scoping of the literature, the topic area (1) was defined through deliberation and a series of prompts, such as outlining issues related to current practices and justifying why these issues would be worth investigating [37,38]. A problem statement was drafted, and from this the research aim and objectives were defined (2). Key terms and their synonyms were identified (3) from the component parts of the research aim and trialed with different databases to find the right balance between specificity and sensitivity. The following keyword string was determined: TITLE ("sustainab*") AND TITLE-ABS-KEY ("higher education" OR "universit" OR "college" OR "campus") AND TITLE-ABS-KEY ("organization* change" OR "change management"). The time frame for this review was set for papers published between 2005 to 2020, as this coincides with an increasing number of authors calling for approaches that aim to embed sustainability holistically in HEIs (e.g., $[39,40])$.

To ensure comprehensiveness, six databases were selected (4), ranging from large and multidisciplinary to discipline specific. The databases searched in September 2020 were Web of Science, Scopus, JSTOR, ProQuest, Taylor and Francis, and Emerald. Additionally, the databases of the International Journal on Sustainability in Higher Education (IJSHE) and the Journal of Cleaner Production were searched, since they have published the largest number of papers on sustainability in higher education [41].

Before scanning and assessing papers (5), inclusion and exclusion criteria were specified in line with the aim of the review. To be included, papers had to use empirical data, describe the research question and purpose, detail research methods, report and interpret results, and discuss possible implications. Additionally, papers had to fulfil three criteria related to the aim and the theoretical framework of the review. First, they had to document a study conducted at a HEI or HEIs, and for studies at the faculty or department level, change had to be linked to the wider organization. Second, papers had to document an approach aiming to embed sustainability holistically into the organization, or link change at one or more HEI sub-system to change at the organizational level. Third, articles had to document an organizational change approach, focusing on at least one of the change factors outlined in the theoretical framework.

As recommended by Pickering [42], to improve rigor and transparency of reporting, the guidelines for Preferred Reporting Items for Systematic reviews and Meta-Analyses (PRISMA) [43] were followed during the search and assessment processes (see Figure 2). First, records were identified through database searching and then imported into a reference manager. After removing duplicates, titles and abstracts were screened. At this stage, review papers, conference proceedings, book chapters, and grey literature, as well as unrelated publications were excluded, while peer-reviewed, original research articles published in English language academic journals were included. The included full-text articles were read and assessed for eligibility, and a reference cross-check was conducted to identify additional publications, which were then screened and assessed according to the same criteria. Out of the 106 full-text articles assessed for eligibility, 73 were excluded with reason (see Table 1). While searching and assessment was conducted by the principal author, a random sample of articles (5.7\% of total) was evaluated by the co-authors, with decisions for inclusion or exclusion being consistent across all authors. 


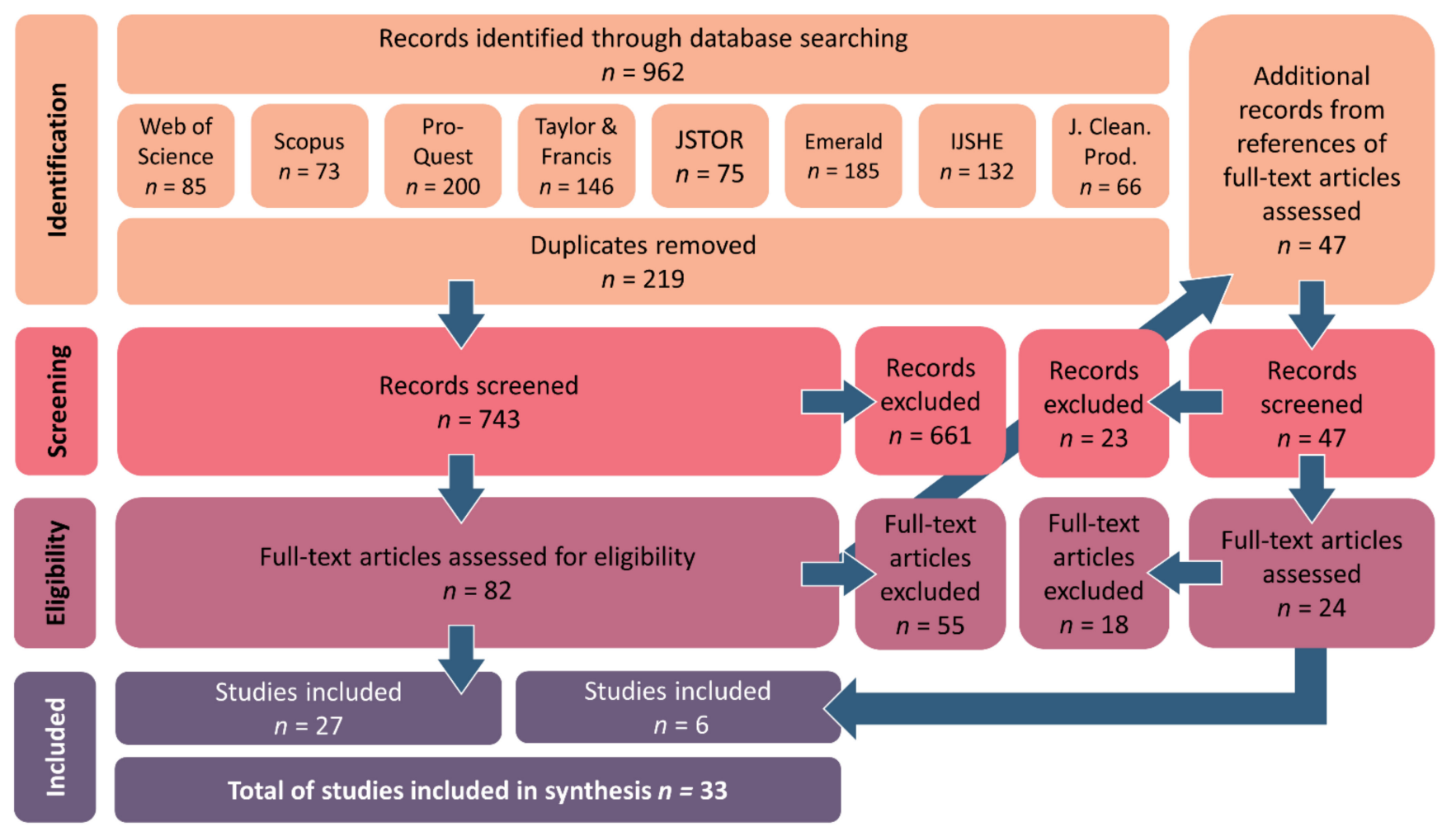

Figure 2. PRISMA flowchart illustrating the process of finding and selecting literature, adapted from Moher et al. [43].

Table 1. Number of full-text articles excluded with reason.

\begin{tabular}{ccc}
\hline Inclusion/Exclusion Criteria & Number of Papers Excluded & \% of Papers Excluded \\
\hline Quality & 48 & $65.8 \%$ \\
Whole-institution approach & 14 & $19.2 \%$ \\
Org. change approach & 9 & $12.3 \%$ \\
HEI focus & 2 & $2.7 \%$ \\
\hline Total excluded & 73 & $100 \%$ \\
\hline
\end{tabular}

During the second phase of the review, an Excel database was created and structured (6) in line with the research objectives and the theoretical framework, containing three main categories: bibliographic information, methodology and methods, and change factors observed. For each overarching category, sub-categories were derived from other review papers (e.g., $[12,22,43,44])$, the preliminary scoping of relevant literature, and inductively determined during the assessment process. After entering the first $10 \%$ of papers (7), sub-categories were revised and updated (8). This included the creation of a separate category to distinguish change factors merely described in a paper, and change factors representing a paper's principal research focus.

Consequently, from each paper, the following information was entered in the database (9):

- $\quad$ author(s), journal name, and year of publication;

- geographic scope and scope of analysis;

- $\quad$ research design, the principal research method, and type of data used;

- $\quad$ internal and external context factors (e.g., organizational structure and government);

- content factors constituting:

$\bigcirc \quad$ the institutional framework (e.g., policy and strategy);

$\bigcirc \quad$ campus operations (e.g., transport);

$\bigcirc \quad$ education (e.g., courses on sustainability);

$\bigcirc \quad$ research (e.g., research center);

$\bigcirc \quad$ outreach and collaboration (e.g., sustainability partnerships); 
on-campus experience (e.g., engagement);

assessment and reporting (e.g., sustainability assessment);

- $\quad$ processes factors related to:

$\bigcirc \quad$ human factors (e.g., perceptions);

0 type of change (e.g., pluralistic);

drivers and barriers;

- $\quad$ leadership factors (e.g., top-down).

The database was then analyzed (10) to identify patterns and gaps in the literature.

\section{Results}

A total of 33 articles on organizational change management approaches that aim to embed sustainability holistically in HEIs were identified and analyzed (for a complete list of articles see Appendix A). The first part of the results introduces where, when, and by whom research was conducted, and what type of research design and methods were used. The second part presents the change factors observed and how they were examined in the literature.

\subsection{Characteristics of the Literature}

The vast majority of papers (97\%) were published after 2011 (Table 2). This reflects the increasing number of publications in sustainability in higher education research in general [41] but also suggests that the literature covered in this review has emerged as a research area only in the past decade. The bulk of papers was published in just three journals: IJSHE (30.3\%), the Journal of Cleaner Production (27.3\%), and Sustainability (21.2\%). The remainder $(21.2 \%)$ was published in different journals, most of them within the field of higher education studies.

As for the geographic scope, most papers (39.4\%) examined change at one institution (local), a slightly smaller percentage $(27.3 \%)$ looked at two or more institutions within a country (national), and a third (33.3\%) studied change at institutions across two or more different countries (international). As for the papers with local or national scope, the majority came from Europe, North America, and Australia, whereas international studies were mostly based on the experience of European, North, and South American HEIs. Papers were also classified according to their scope of analysis. Out of the 33 papers, seven $(21.2 \%)$ described change at the sub-system level (e.g., campus operations), 25 papers $(75.7 \%)$ at the organizational level, and one (3\%) analyzed change in the wider sector.

The most prominent research designs were case and multiple case studies $(57.6 \%)$ followed by cross-sectional studies (30.3\%) and exploratory studies (12.1\%). Most publications either used interviews $(45.4 \%)$ or surveys $(39.4 \%)$ as their principal research method. Other research methods used were focus groups, document analysis, and a participatory workshop. As for the type of data collected, most papers (60.6\%) used qualitative data, a small number $(15.2 \%)$ quantitative data, and about a fourth $(24.2 \%)$ mixed data. Finally, the majority of authors (78.8\%) did not explicitly state in which organization theory their paper was grounded in, but apparently drew on a range of different theories, including postmodern and realist perspectives, organizational learning, and contingency theory. 
Table 2. Characteristics of papers published (2005-2020) on organizational change management for sustainability in HEIs.

\begin{tabular}{|c|c|c|}
\hline Category & Number of Papers & $\%$ of Total \\
\hline Total & 33 & $100 \%$ \\
\hline \multicolumn{3}{|l|}{ Year of publication } \\
\hline 1st 6 years (2005-2010) & 1 & $3.0 \%$ \\
\hline 2nd 5 years (2011-2015) & 10 & $30.3 \%$ \\
\hline 3rd 5 years (2016-2020) & 22 & $66.7 \%$ \\
\hline \multicolumn{3}{|l|}{ Journal published in } \\
\hline IJSHE & 10 & $30.3 \%$ \\
\hline Journal of Cleaner Production & 9 & $27.3 \%$ \\
\hline Sustainability & 7 & $21.2 \%$ \\
\hline Other & 7 & $21.2 \%$ \\
\hline \multicolumn{3}{|l|}{ Geographic scope } \\
\hline Local & 13 & $39.4 \%$ \\
\hline National & 9 & $27.3 \%$ \\
\hline International & 11 & $33.3 \%$ \\
\hline \multicolumn{3}{|l|}{ Scope of analysis } \\
\hline Sub-system & 7 & $21.2 \%$ \\
\hline Organization & 25 & $75.7 \%$ \\
\hline Sector & 1 & $3.0 \%$ \\
\hline \multicolumn{3}{|l|}{ Research design } \\
\hline Case study & 12 & $36.4 \%$ \\
\hline Multiple case study & 7 & $21.2 \%$ \\
\hline Cross-sectional & 10 & $30.3 \%$ \\
\hline Exploratory & 4 & $12.1 \%$ \\
\hline \multicolumn{3}{|l|}{ Principal research method } \\
\hline Interviews & 15 & $45.4 \%$ \\
\hline Survey & 13 & $39.4 \%$ \\
\hline Focus groups & 2 & $6.1 \%$ \\
\hline Document analysis & 2 & $6.1 \%$ \\
\hline Workshop & 1 & $3.0 \%$ \\
\hline \multicolumn{3}{|l|}{ Data type } \\
\hline Qualitative & 20 & $60.6 \%$ \\
\hline Quantitative & 5 & $15.2 \%$ \\
\hline Mixed & 8 & $24.2 \%$ \\
\hline
\end{tabular}

\subsection{Overview of Change Factors}

Within the four overarching change categories, context, content, process, and leadership, a total of 285 database entries were made, with an average of 8.6 per paper and a standard deviation of 4.6. Out of those, 76 entries were classified as the principal research focus, with an average of 2.3 per article and a standard deviation of 0.9. Content factors exhibited the largest number of entries $(n=114)$, followed by process $(n=92)$, context $(n=65)$, and leadership factors $(n=14)$ (see Figure 3$)$. When quantifying principal research foci, process factors were examined most often $(n=46)$, followed by content factors $(n=22)$, with context $(n=4)$ and leadership factors far behind $(n=4)$. In the following, a closer analysis of change context, content, processes, and leadership and their sub-categories is provided. Within each category, studies were highlighted that presented new approaches to managing change for sustainability at HEIs or contributed to the understanding of specific change factors and their impact on organizational change. 


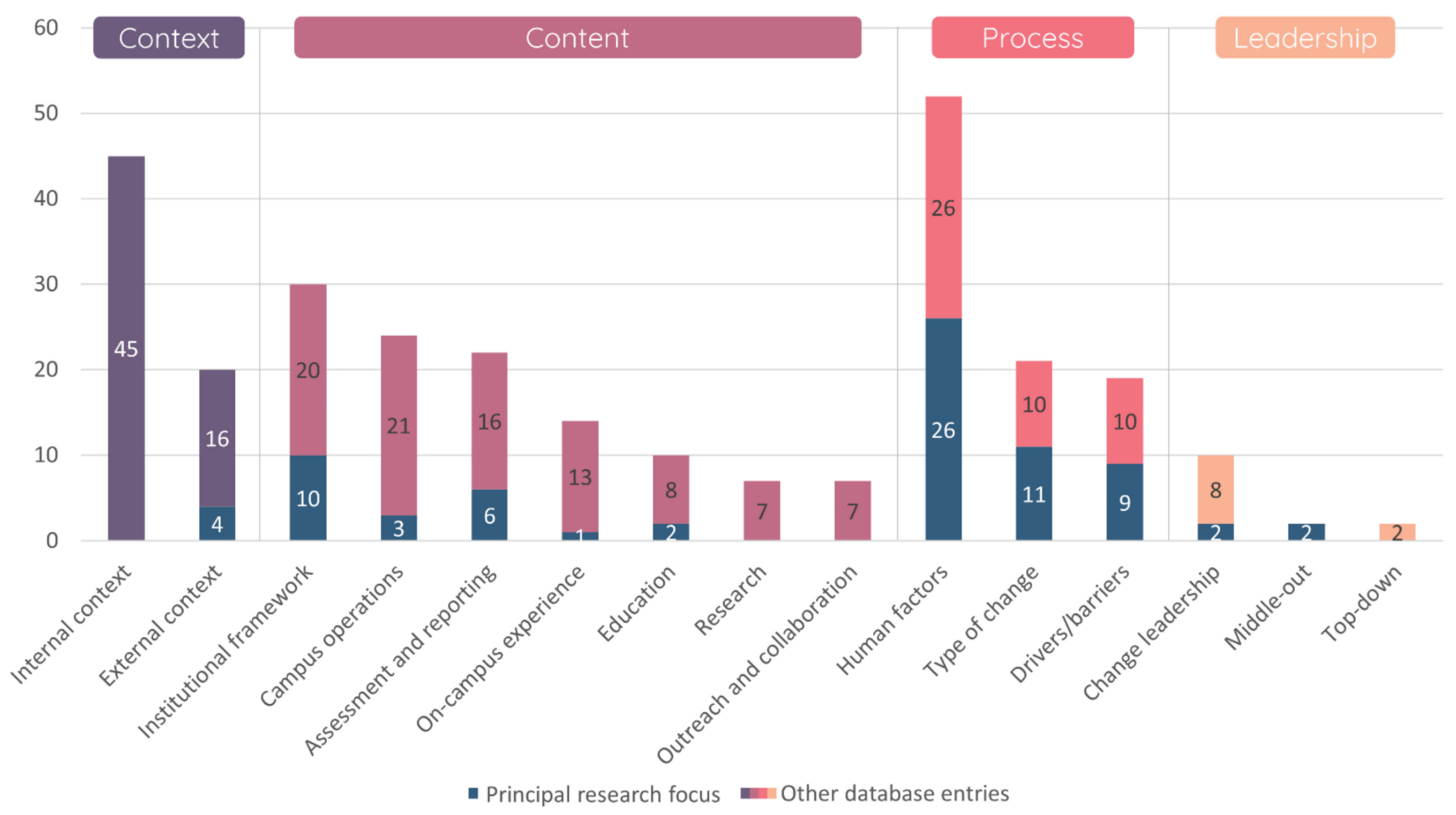

Figure 3. Change factors by frequency of database entries.

\subsubsection{Context}

Overall, 22 papers (66.6\% of total) contained at least one database entry constituting an internal or external context factor. Regarding internal context, organizational structures ( $n=13)$, sustainability networks $(n=9)$, and senior staff support $(n=8)$ were included most frequently (see Figure 4$)$. As for the external context, sectoral $(n=8)$ or government $(n=7)$ initiatives were mentioned most often. Despite the large number of database entries, only a few papers focused on context factors. This is due to most scholars including context factors to describe the study background (e.g., [44,45]), usually to enhance transferability of the change approach taken. Several papers pointed out the importance of certain contexts to enable change, ranging from general recommendations (e.g., [46,47]) to the definition of success factors for specific interventions (e.g., [18,48]). Only four papers highlighted how context factors can impact organizational change. For instance, Farinha et al. [49] found that sectoral initiatives like the UN Decade of Education for Sustainable Development had limited effect on Portuguese HEIs, whereas Bohunovsky et al. [50] claimed that a national university network acted like a major driver of change, particularly for HEIs starting their journey towards sustainability. Similarly, Lambrechts et al. [51] report positive impacts from professional development initiatives driven by the government to facilitate the incorporation of sustainability into competence-based education. 


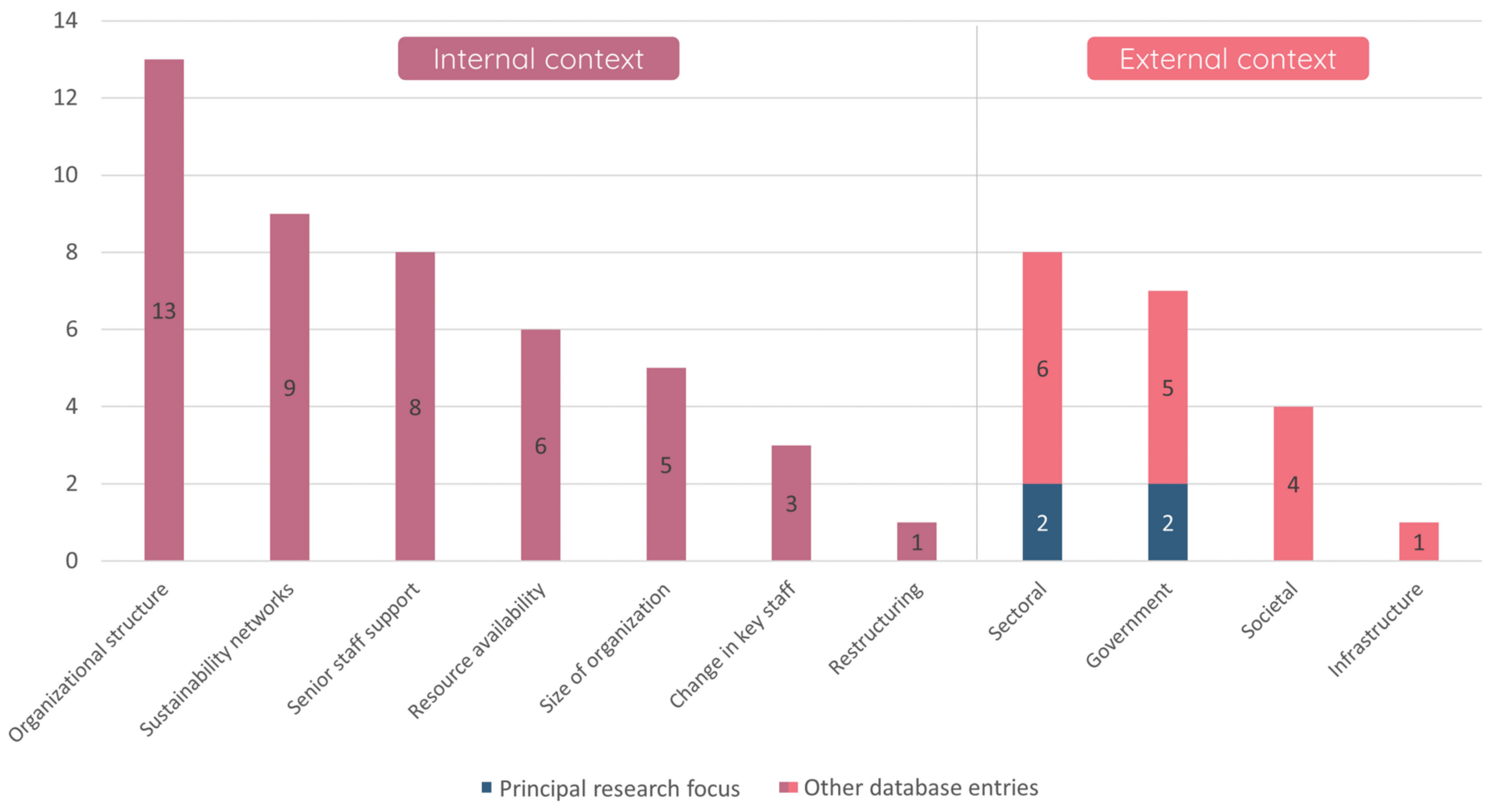

Figure 4. Internal and external context factors: sub-categories by frequency of database entries.

\subsubsection{Content}

Most papers ( $87.9 \%$ of total) included at least one database entry constituting a content factor. Institutional framework exhibited most database entries, particularly vision and mission $(n=10)$, policy and strategy $(n=9)$, and sustainability offices $(n=8)$ (see Figure 5). This and the large number of entries constituting a principal research focus highlight the importance of integrating sustainability into the institutional framework when aiming at holistic change. It was suggested that broader changes can cascade down from the vision and mission of an organization [52], especially when built around common values [53], and supported by a large number of stakeholders [54]. Embedding sustainability in policy and strategy is also seen as a critical step to make sustainability a formal part of the organization [55], and HEIs that have done so are reportedly performing well in other areas in terms of sustainability [56]. Similarly, establishing a sustainability office is perceived as a milestone for institutionalizing sustainability [55], although depending on context, their work might face a number of constraints [57].

Campus operations come in second regarding the frequency of database entries $(n=24)$, spread out across various operational activities. Despite the large number of entries, only three constitute the principal research focus within this category. Amongst those, most notable are the studies of Hancock and Nuttman [58], where an intervention to increase the uptake of sustainable travel led to the establishment of a sustainability office and committee, and Disterheft et al. [59], who showed that Environmental Management Systems (EMS) paired with a participatory approach can enhance cross-departmental collaboration and even lead to an institution-wide paradigm shift. 


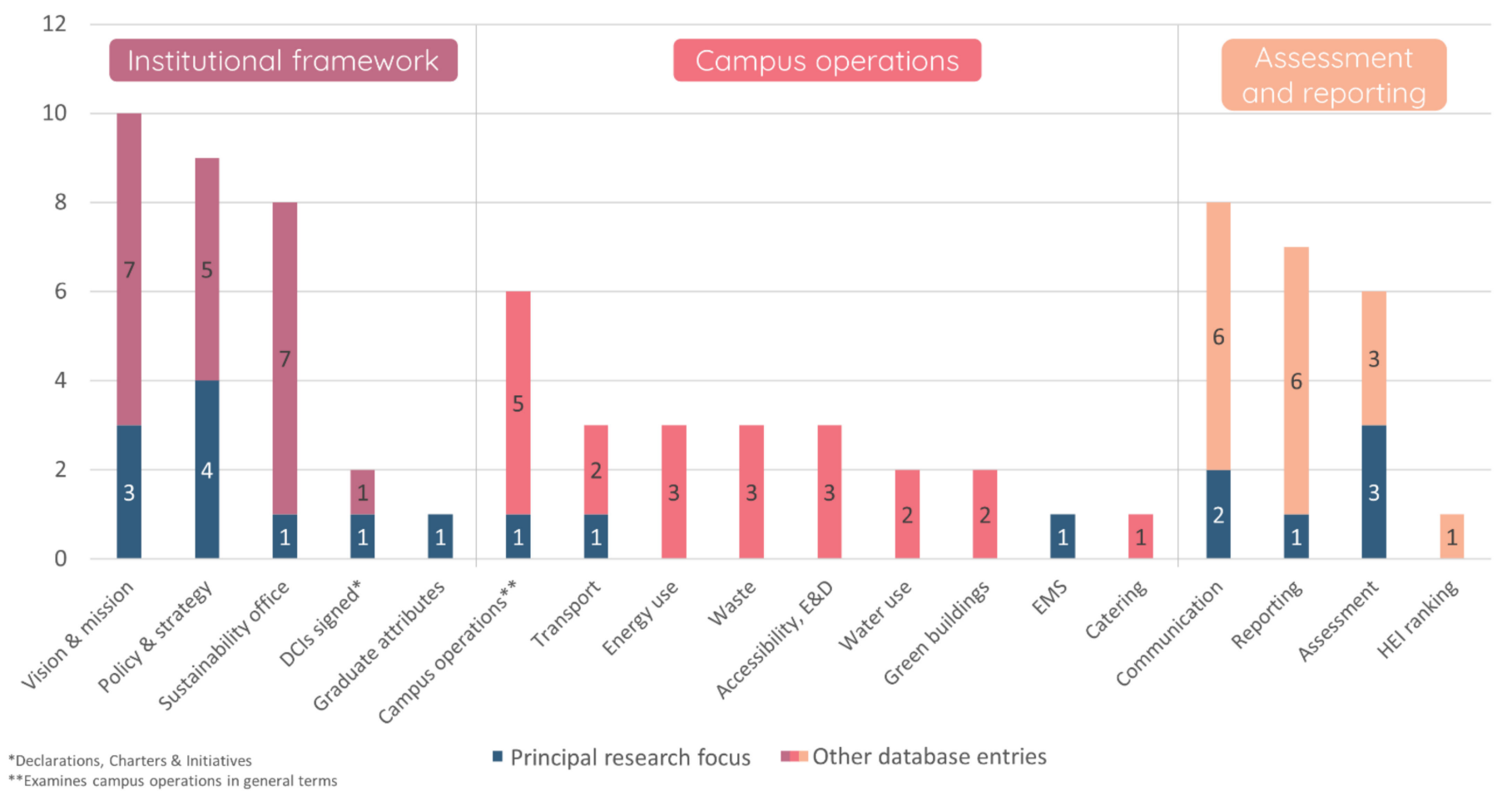

Figure 5. Institutional framework, campus operations, assessment and reporting: subcategories by frequency of database entries.

The third HEI sub-system standing out is assessment and reporting, with 22 database entries and six of them being classified as the principal research focus. Assessment is usually defined as an auditing tool, and reporting as a way of disclosing and communicating information, but in practice both concepts overlap [60,61]. Reporting and assessment can play different roles to promote change, depending on organizational context and stakeholders involved [60]. It can act as an instigator and lead to incremental changes through fostering dialogue and raising awareness [60,61], or aid in taking stock of the status quo and in this way support planning and policy development [61,62]. When taking a participatory approach, campus assessments can also break silos through creating interorganizational networks [60]. As for the remaining sub-systems, outreach and collaboration, on-campus experience, education, and research, the frequency of entries is considerably lower, particularly when considering the number of entries comprising the principal research focus of a paper (see Figure 3).

\subsubsection{Process}

The vast majority of papers $(93.9 \%$ of total) included at least one database entry constituting a process factor, with human factors having most database entries. One of the major themes is the conceptualization of sustainability $(n=11)$ (see Figure 6). A shared understanding of what sustainability means in a HEI context is often seen as a basic prerequisite for organizational change $[54,63]$. Since sustainability is a highly ambiguous term with multiple potential interpretations [64], scholars suggest participatory approaches to enhance conceptual understanding and consensus-building $[48,65]$. A divergent point of view is put forward by Sylvestre et al. [66], claiming that rather than trying to define sustainability in one way, a continuous dialogue and multiple visions of sustainability should be developed. 


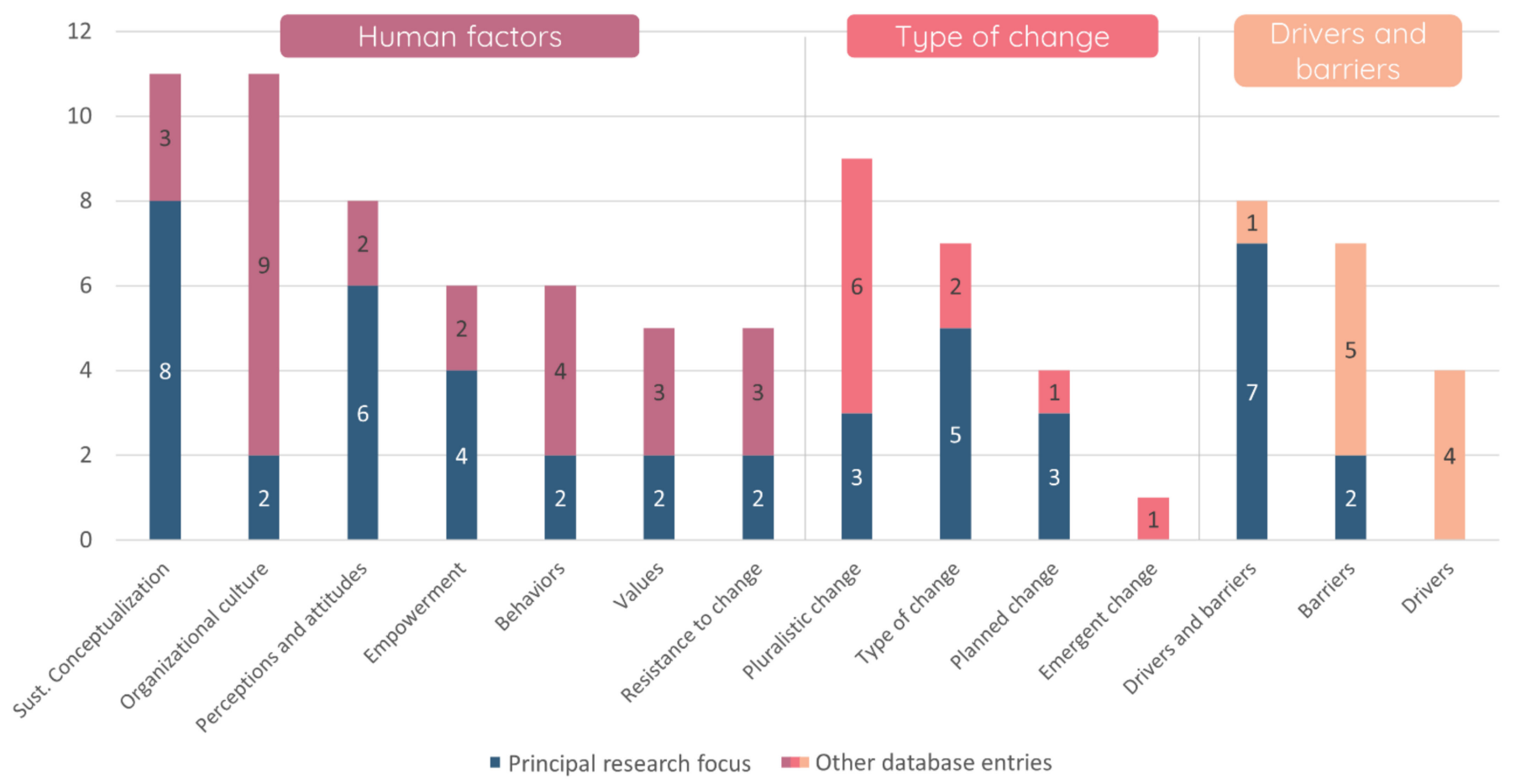

Figure 6. Process factors: sub-categories by frequency of database entries.

While organizational culture of HEIs is mentioned frequently $(n=11)$, it is often cited as a barrier to organizational change (e.g., [66]), or as a factor to consider when implementing change initiatives (e.g., [55]). An important exception here is the study by Niedlich et al. [67], investigating links between organizational culture and sustainability governance. Other prevalent factors are perceptions and attitudes $(n=8)$ and empowerment $(n=6)$. Perceptions and attitudes are seen as key for measuring the impact of engagement campaigns (e.g., [58]) or to inform a HEI's sustainability strategy (e.g., [48]). As for empowerment, providing stakeholders with the necessary skills and resources to foster sustainability at HEIs is a dominant theme (e.g., [51]), as is the interplay between academic freedom, culture in HEIs, and organizational change towards sustainability (e.g., [68]).

When considering the type of change, pluralistic or participatory approaches had most database entries $(n=9)$. Papers had to be distinguished between those merely documenting a pluralistic approach and those actively researching them. For instance, Disterheft et al. [18] examine critical success factors for implementing participatory approaches throughout the different HEI sub-systems, such as campus operations and on-campus experience. Another set of papers $(n=7)$ looks at the different types of change approaches taken, contrasting their advantages and disadvantages (e.g., [60]).

As for drivers and barriers, the papers included in this review examine both $(n=8)$, or barriers only $(n=7)$, and they do so in multiple ways. For instance, Barth [26] analyzes the way different drivers and barriers influence each other, showing that a driver in one organizational context can be a barrier in another. Blanco-Portela et al. [47] rank drivers and barriers by importance, and Hugé et al. [55] illustrate drivers and barriers that are likely to appear during the different stages of organizational transformation. While these studies look at drivers and barriers on the organizational level, other papers examine them in the context of specific initiatives. For instance, Leal Filho et al. [69] identify barriers to planning change at HEIs, and Hancock and Nuttman [58] examine barriers to enhance sustainable transport. 


\subsubsection{Leadership}

Overall, 14 papers ( $42.2 \%$ of total) contained at least one database entry constituting a leadership factor, and out of those, the majority contrasted different approaches of change leadership and their impact on organizational change (e.g., [50]) (see Figure 3). Most of these papers attach leadership to specific stakeholders and the degree of authority they wield. For instance, a common view is that top-management can have significant impact on sustainability performance, either through directing strategy and allocating budgets, or acting as a role model for other staff (e.g., [44]). However, top-down approaches can also cause resistance when they clash with staff values, or when stakeholders feel that they were excluded from decision-making [70]. This particularly applies to HEIs, where faculty attach great importance to autonomy [63]. A fresh perspective is presented by Avissar et al. [68], who investigate distributed leadership and leadership activity that arises from different situational contexts and interactions between leaders and followers.

\section{Discussion}

Four main findings emerge from the analysis: First, integrating sustainability in the institutional framework is indispensable when aiming at holistic change. Second, a shared understanding of sustainability is a basic requirement to organization-wide transformation. Third, assessment and reporting are key to initiate and drive change. Fourth, there is an urgent need for more research into context and leadership factors.

\subsection{Embedding Sustainability in the Institutional Framework}

Contrary to the wider discourse on sustainability in HEIs, still dominated by campus operations and education for sustainability [71,72], the literature on holistic approaches puts emphasis on content factors comprising the institutional framework. This confirms the idea that vision, strategy, policies, and governance structures are significant leverage points for transforming an organizational system, since they can influence decision-making, resource distribution, and stakeholder behaviors across all other sub-systems and the organization as a whole [20,73].

Integrating sustainability in the institutional framework is not a precondition for engaging with sustainability initiatives, but it is an indispensable step when aiming for holistic change [55]. It requires support from senior level stakeholders [50], which can be achieved through continuous lobbying from sustainability advocacy groups, or through changes in internal or external context [44]. However, changes to the institutional framework in a top-down manner are likely to meet resistance or apathy, since broadly based ownership and commitment is needed for institution-wide change [70].

\subsection{Pluralistic Approaches to Conceptualize Sustainability}

Several authors suggest that an effective way to garner ample support is through participatory approaches that aim to create a shared understanding of sustainability in a higher education context (e.g., [54,65]). This includes discussing the purpose of HEIs with respect to research, education, and its role in society, which can bring hidden contradictions to the fore and prevent covert resistance $[63,66,67]$. Moreover, combined with communications that emphasize the need for change, these discussions can shift how stakeholders view functions and goals of HEIs. Changing the dominant mind-set is one of the most powerful leverage points in an organizational system [73], and most organizational change models emphasize that without a compelling need, it is impossible to 'unfreeze' the status quo [74,75].

While conceptualizing sustainability through a participatory approach is a critical step for holistic transformation, several barriers need to be overcome. Change towards sustainability is often initiated from estates and campus services departments, where staff might lack resources, skills, and permission to conduct large-scale engagement [69]. Moreover, participatory approaches can backfire, for instance when stakeholders lack participatory skills, or when results are dismissed by senior staff or lost in bureaucracy [18]. Therefore, although not a prerequisite, support from senior staff increases likelihood of success [54]. 


\subsection{Building Networks through Assessment and Reporting}

Another promising constellation of change factors consists of assessment and reporting, paired with communication and a pluralistic approach to change. A variety of sustainability assessment tools for HEIs include reporting and benchmarking functions, such as the Assessment Instrument for Sustainability in Higher Education, or the EAUC Leadership Scorecard. While different tools come with their own scope and methods, a common denominator is that they can drive holistic change in several ways. Results from assessment can be used to garner support from senior level stakeholders, for instance by establishing a performance gap [76]. This rings particularly true as sustainability performance of HEIs have received increasing attention, with league tables such as the Times Higher Education Impact Ranking seeing participation rise by almost 150\% between 2019 and 2021 [77].

However, the most significant way campus assessments can drive change is when used to engage with a wide range of stakeholders, organizing them into cross-departmental sustainability teams. Establishing and empowering these teams equates to changing the structure of an organizational system, an action representing a leverage point that can significantly advance holistic change [73]. When having the right people on board, sustainability teams can improve planning and decision-making [20] and help link assessment results to strategy and policy development [78]. Furthermore, they can increase the reach of communications through informal channels and in this way spread awareness and create a sense of urgency [61]. Assessment and reporting are particularly useful in contexts where sustainability is managed from estates and campus services departments and has not penetrated the wider organization, since it provides a license to engage with stakeholders and create support networks necessary for holistic change.

\subsection{Missing Pieces: Change Context and Leadership}

While the literature included in this review shines a light on the importance of content and process factors, there is a gap when it comes to change context and leadership. Context factors are mostly provided as study background, which is useful for situating a study and assessing transferability [26]. However, to understand and design change it is necessary to comprehend how context factors impact change and how a shift in context can trigger change. This could be a change in external context, such as a social protest movement, or in internal context, for example organizational restructuring. Future studies could provide insights how changes in context could be used as a window of opportunity for initiating or accelerating the integration of sustainability in HEIs, or how to best plan and mitigate against potential negative impacts from a change in context, such as budget cuts or turnover of key staff.

Most papers including leadership factors do so often incidentally, and beside for a few exceptions (e.g., [68]) do not add to theory nor offer insights for practice. This is a major issue since good leadership is key to holistic change [20]. Considering the strong connection between leadership and organizational change [27] and the increasing interest in sustainability leadership, the apparent lack of research in this area is concerning. Future studies on leadership for sustainability in HEIs could expand on approaches from the existing literature on leadership and adapt theory and practice to higher education context, for instance, by analyzing environmental-transformative leadership and its impact on organizational change or by examining how different leadership behaviors can create capacities for institution-wide change.

\section{Conclusions}

The literature on sustainability in higher education has been repeatedly criticized for the disproportionate number of papers documenting siloed approaches and for being too descriptive [11]. While there is still room for improvement, particularly regarding explicitness of organization theory and theoretical frameworks used, this review has shown that there is an increasing number of high-quality papers detailing organizational change 
approaches that aim to embed sustainability holistically into HEIs. It also demonstrated that this emerging area is conceptually diverse and covers a wide range of topics. Within those, a particular focus is on change processes and the human side of change, such as conceptualization of sustainability, perceptions, attitudes, and behaviors. Other focal points are content factors comprising the institutional framework and to a lesser extent assessment and reporting.

This emphasizes that implementing changes within the institutional framework and assessment and reporting are likely to affect the wider organizational system, often through activating leverage points for holistic change. Conversely, changes in the HEI sub-systems of campus operations or education usually do not lead to change at the institutional level $[79,80]$. That said, it is possible to affect wider change from these sub-systems, as has been illustrated by studies featured in this review [43,58,59]. Common features of these studies are that they focus on change processes, are strategically designed, take a pluralistic approach or pay close attention to human factors, and touch upon at least one leverage point for systemic change. This highlights the value of strategic and reflective actions, the importance of understanding and actively shaping change processes, and that change towards sustainability is inherently pluralistic and requires broad stakeholder input and commitment.

By summarizing and synthesizing the literature on holistic approaches to change, this review serves as a reference point and encourages researchers and practitioners to adapt, build upon, and add to the insights from the papers presented. The review also identified several research gaps, most notably around change context and leadership, and content factors comprising outreach and collaboration, education, research, and on-campus experience. Nevertheless, there are also gaps within other areas, such as the institutional framework. For instance, research could add to the study of Leal Filho et al. [57] and investigate to what extent establishing a sustainability office might lead to stakeholders shirking responsibility for action. More research is also needed on sustainability assessment and reporting, since it is still one of the more neglected sub-systems when it comes to implementation [12]. Future research could investigate barriers and drivers to the adoption of assessment and reporting practices, and how to best use them to create cross-departmental networks. Amongst process factors, further studies analyzing how and in what ways HEIs conceptualize sustainability are needed, particularly from Latin American, African, and Asian HEIs. Similarly, more research is required to demonstrate how organizational culture at HEIs can be assessed and leveraged for change towards sustainability.

\section{Limitations}

Systematic review techniques reduce biases, but they cannot remove them completely [33]. For instance, this review only included papers published in English, which might introduce a language bias. However, since English language dominates the international scientific literature, the bias should not be very pronounced [81]. A further limitation, also found in the broader sustainability in higher education literature, is the geographical coverage of publications, featuring mainly European and North American researchers and institutions [41,71]. This is mitigated by articles taking an international scope, but studies from Asian and African countries are still missing. Lastly, a problem concerning all literature reviews is publication bias. While this cannot be controlled, the methodological and methodical diversity of papers included in this review help to reduce this bias.

Author Contributions: Conceptualization, N.A.R., B.G., and I.C.; methodology, N.A.R.; validation, B.G. and I.C.; formal analysis, N.A.R.; investigation, N.A.R.; data curation, N.A.R.; writing-original draft preparation, N.A.R.; writing-review and editing, N.A.R., B.G., and I.C.; visualization, N.A.R.; supervision, N.A.R.; project administration, N.A.R.; funding acquisition, N.A.R. All authors have read and agreed to the published version of the manuscript.

Funding: This research is part of the corresponding author's Practitioner Doctorate in Sustainability, which is fully funded by the University of Surrey's Sustainability and Energy Team. 
Data Availability Statement: The data presented in this study are openly available in openresearch.surrey.ac.uk at doi:10.15126/surreydata.900009.

Acknowledgments: The authors would like to thank the reviewers for the valuable feedback. The corresponding author would also like to thank all colleagues at CES and the Sustainability Team, and Thomas Parrott, Head of Energy and Sustainability at the University of Surrey, for his continued support.

Conflicts of Interest: The authors declare no conflict of interest. The funders had no role in the design of the study; in the collection, analyses, or interpretation of data; in the writing of the manuscript; or in the decision to publish the results.

\section{Appendix A}

Table 1 contains a complete list of articles reviewed, including main author(s), and year of publication, journal name, and principal research focus.

Table 1. List of articles reviewed.

\begin{tabular}{|c|c|c|c|}
\hline Author(s) & Year & Journal & Principal Research Focus \\
\hline Agostino and Dal Molin [82] & 2016 & IJSHE & Sustainability conceptualization \\
\hline Akins et al. [44] & 2019 & Sustainability & Drivers and barriers \\
\hline Aleixo et al. [83] & 2018 & IJSHE & Sustainability conceptualization \\
\hline Arroyo [60] & 2017 & J. Clean. Prod & Sustainability assessment \\
\hline Avissar et al. [68] & 2018 & IJSHE & Leadership \\
\hline Awuzie and Abuzeinab [46] & 2019 & Sustainability & Interlinkage of change factors \\
\hline Baker-Shelley et al. [84] & 2020 & $\begin{array}{l}\text { International Journal of Sustainable Development and } \\
\text { World Ecology }\end{array}$ & Interlinkage of change factors \\
\hline Barth [26] & 2013 & IJSHE & Types of change \\
\hline Blanco-Portela et al. [47] & 2018 & Sustainability & Drivers and barriers \\
\hline Bien and Sassen [63] & 2020 & J. Clean. Prod & Sustainability conceptualization \\
\hline Bohunovsky et al. [50] & 2020 & Sustainability & Types of change \\
\hline Ceulemans et al. [61] & 2015 & Sustainability & Sustainability reporting \\
\hline Conner et al. [48] & 2018 & Sustainability & Sustainability conceptualization \\
\hline Disterheft et al. [59] & 2012 & J. Clean. Prod & Energy management systems \\
\hline Disterheft et al. [18] & 2015 & J. Clean. Prod & Participatory approaches \\
\hline Dyball et al. [70] & 2015 & Accounting, Auditing \& Accountability & Resistance to change \\
\hline Farinha et al. [49] & 2018 & IJSHE & Sector networks \\
\hline Hancock and Nuttman [58] & 2014 & J. Clean. Prod & Sustainable transport \\
\hline Hugé et al. [55] & 2018 & J. Clean. Prod & Types of change \\
\hline Lambrechts [62] & 2015 & Assessment $\mathcal{E}$ Evaluation in $\mathrm{HE}$ & Sustainability assessment \\
\hline Lambrechts et al. [51] & 2017 & IJSHE & Empowerment \\
\hline Leal Filho et al. [85] & 2017 & Journal of Integrative Environmental Science & Barriers to change \\
\hline Leal Filho et al. [56] & 2018 & IJSHE & Policy \\
\hline Leal Filho et al. [57] & 2019 & J. Clean. Prod & Sustainability offices \\
\hline Leal Filho et al. [69] & 2019 & J. Clean. Prod & Planned change \\
\hline Lee et al. [52] & 2013 & IJSHE & Sustainability in vision \\
\hline Lozano et al. [12] & 2014 & J. Clean. Prod & Sustainability declarations \\
\hline Mahmud et al. [86] & 2019 & International Journal of Innovation, Creativity and Change & Drivers and barriers \\
\hline Niedlich et al. [67] & 2020 & Higher education quarterly & Organizational culture \\
\hline Pollock et al. [54] & 2009 & IJSHE & Sustainability conceptualization \\
\hline Ribeiro et al. [53] & 2016 & IJSHE & Values \\
\hline Schopp et al. [65] & 2020 & Sustainability & Sustainability conceptualization \\
\hline Sylvestre et al. [66] & 2013 & Journal of Education for SD & Sustainability conceptualization \\
\hline
\end{tabular}

\section{References}

1. Orr, D. The Nature of Design: Ecology, Culture and Human Intention; Oxford University Press: Oxford, UK, 2002.

2. United Nations. Report of the United Nations Conference on Environment and Development Rio Declaration. In Proceedings of the United Nations Conference on Environment and Development, Rio de Janeiro, Brazil, 3-14 June 1992.

3. The United Nations Environment Programme. Stockholm Declaration on the Environment; The United Nations Environment Programme: Panama City, Panama, 1972. 
4. WBGU World in Transition: A Social Contract for Sustinability; WBGU: Berlin, Germany, 2011.

5. Adams, R.; Martin, S.; Boom, K. University culture and sustainability: Designing and implementing an enabling framework. J. Clean. Prod. 2018, 171, 434-445. [CrossRef]

6. Ramos, T.B.; Caeiro, S.; Van Hoof, B.; Lozano, R.; Huisingh, D.; Ceulemans, K. Experiences from the implementation of sustainable development in higher education institutions: Environmental Management for Sustainable Universities. J. Clean. Prod. 2015, 106, 3-10. [CrossRef]

7. Newman, J. An organisational change management framework for sustainability. Greener Manag. Int. 2012, 57, 65-75. [CrossRef]

8. Posner, S.M.; Stuart, R. Understanding and advancing campus sustainability using a systems framework. Int. J. Sustain. High. Educ. 2013, 14, 264-277. [CrossRef]

9. Stephens, J.C.; Graham, A.C. Toward an empirical research agenda for sustainability in higher education: Exploring the transition management framework. J. Clean. Prod. 2010, 18, 611-618. [CrossRef]

10. Corcoran, P.B.; Walker, K.E.; Wals, A.E.J. Case studies, make-your-case studies, and case stories: A critique of case-study methodology in sustainability in higher education. Environ. Educ. Res. 2004, 10, 7-21. [CrossRef]

11. Barth, M.; Rieckmann, M. State of the Art in Research on Higher Education for Sustainable Development. In Routledge Handbook of Higher Education for Sustainable Development; Barth, M., Michelsen, G., Rieckmann, M., Thomas, I., Eds.; Routledge: London, UK, 2016; pp. 100-113.

12. Lozano, R.; Ceulemans, K.; Alonso-Almeida, M.; Huisingh, D.; Lozano, F.J.; Waas, T.; Lambrechts, W.; Lukman, R.; Hugé, J. A review of commitment and implementation of sustainable development in higher education: Results from a worldwide survey. $J$. Clean. Prod. 2014, 108, 1-18. [CrossRef]

13. Pettigrew, A.M.; Whipp, R. Managing Change for Competitive Success; Blackwell Publishing: Oxford, UK, 1991.

14. Ha, H. Change Management for Sustainability; Business Expert Press LLC.: New York, NY, USA, 2014.

15. Petticrew, M. Systematic reviews from astronomy to zoology: Myths and misconceptions. Br. Med. J. 2001, 322, 98-101. [CrossRef]

16. Randolph, J.J. A Guide to Writing the Dissertation Literature Review. Pract. Assess. Res. Eval. 2009, 14, 13.

17. Moore, J. Seven recommendations for creating sustainability education at the university level: A guide for change agents. Int. J. Sustain. High. Educ. 2005, 6, 326-339. [CrossRef]

18. Disterheft, A.; Caeiro, S.; Azeiteiro, U.M.; Filho, W.L. Sustainable universities-A study of critical success factors for participatory approaches. J. Clean. Prod. 2015, 106, 11-21. [CrossRef]

19. Burnes, B. Managing Change: A Strategic Approach to Organisational Dynamics, 4th ed.; Pearson Education: Harlow, UK, 2004.

20. Doppelt, B. Leading Change Toward Sustainability Change-Management Guide for Business, Government and Civil Society, 2nd ed.; Greenleaf Publishing: Sheffield, UK, 2010.

21. Exter, N.; Grayson, D.; Maher, R. Facilitating organizational change for embedding sustainability into academia: A case study. J. Manag. Dev. 2013, 32, 319-332. [CrossRef]

22. Pettigrew, A.M.; Woodman, R.W.; Cameron, K.S. Studying organizational change and development: Challenges for future research. Acad. Manag. J. 2001, 44, 697-713. [CrossRef]

23. Kuipers, B.S.; Higgs, M.; Kickert, W.; Tummers, L.; Grandia, J.; Van Der Voet, J. The management of change in public organizations: A literature review. Public Adm. 2014, 92, 1-20. [CrossRef]

24. Kickert, W.J.M. Managing emergent and complex change: The case of Dutch agencification. Int. Rev. Adm. Sci. 2010, 76, 489-515. [CrossRef]

25. Armenakis, A.; Bedeian, A. Organizational change: A review of theory and research in the 1990s. J. Manage. 1999, 25, 293-315. [CrossRef]

26. Barth, M. Many roads lead to sustainability: A process-oriented analysis of change in higher education. Int. J. Sustain. High. Educ. 2013, 14, 160-175. [CrossRef]

27. Parry, K.W. Leadership and organization theory. In The SAGE Handbook of Leadership; Bryman, A., Collinson, D., Grint, K., Jackson, B., Uhl-Bien, M., Eds.; SAGE Publications: London, UK, 2011; pp. 53-70.

28. Burnes, B.; Hughes, M.; By, R.T. Reimagining organisational change leadership. Leadership 2016, 14, 141-158. [CrossRef]

29. Parkin, S. The Positive Deviant; Earthscan: Oxon, UK, 2010.

30. Buller, J.L. From Change Management to Change Leadership: Change Leadership in Higher Education; John Wiley \& Sons, Inc.: San Francisco, CA, USA, 2014.

31. Brinkhurst, M.; Rose, P.; Maurice, G.; Ackerman, J.D. Achieving campus sustainability: Top-down, bottom-up, or neither? Int. J Sustain. High. Educ. 2011, 12, 338-354. [CrossRef]

32. Hoover, E.; Harder, M.K. What lies beneath the surface? the hidden complexities of organizational change for sustainability in higher education. J. Clean. Prod. 2015, 106, 175-188. [CrossRef]

33. Pickering, C.; Byrne, J. The benefits of publishing systematic quantitative literature reviews for PhD candidates and other early-career researchers. High. Educ. Res. Dev. 2014, 33, 534-548. [CrossRef]

34. Borenstein, M.; Hedges, L.V.; Higgins, J.P.T.; Rothstein, H.R. Introduction to Meta-Analysis; Wiley: London, UK, 2009.

35. Guitart, D.; Pickering, C.; Byrne, J. Past results and future directions in urban community gardens research. Urban For. Urban Green. 2012, 11, 364-373. [CrossRef]

36. Steven, R.; Pickering, C.; Guy Castley, J. A review of the impacts of nature based recreation on birds. J. Environ. Manag. 2011, 92, 2287-2294. [CrossRef] [PubMed] 
37. Bettany-Saltikov, J. How to do a Systematic Literature Review in Nursing: A Step-By-Step Guide; Open University Press: Milton Keynes, UK, 2012; ISBN 9780335242283.

38. Leedy, P.D.; Omrod, J.E. Practical Research: Planning and Design, 10th ed.; Pearson: London, UK, 2010.

39. Sterling, S. Higher education, sustaiability, and the role of systemic learning. In Higher Education and the Challenge of Sustainability: Problematics, Promise, and Practice; Corcoran, P.B., Wals, A.E.J., Eds.; Kluwer Academic Press: Dordrecht, The Netherlands, 2004; pp. $47-70$.

40. Velazquez, L.; Munguia, N.; Platt, A.; Taddei, J. Sustainable university: What can be the matter? J. Clean. Prod. 2006, 14, 810-819. [CrossRef]

41. Hallinger, P.; Chatpinyakoop, C. A Bibliometric Review of Research on Higher Education for Sustainable Development, 1998-2018. Sustainability 2019, 11, 2401. [CrossRef]

42. Pickering, C. Systematic Quantitative Literature Review. Available online: https://www.griffith.edu.au/griffith-sciences/schoolenvironment-science/research/systematic-quantitative-literature-review (accessed on 12 September 2020).

43. Moher, D.; Liberati, A.; Tetzlaff, J.; Altman, D.G. Preferred Reporting Items for Systematic Reviews and Meta-Analyses: The PRISMA Statement. PLoS Med. 2009, 6, e1000097. [CrossRef]

44. Akins, E.E.; Giddens, E.; Glassmeyer, D.; Gruss, A.; Hedden, M.K.; Slinger-Friedman, V.; Weand, M. Sustainability Education and Organizational Change: A Critical Case Study of Barriers and Change Drivers at a Higher Education Institution. Sustainability 2019, 11, 501. [CrossRef]

45. Verhulst, E.; Lambrechts, W. Fostering the incorporation of sustainable development in higher education. Lessons learned from a change management perspective. J. Clean. Prod. 2015, 106, 189-204. [CrossRef]

46. Awuzie, B.O.; Abuzeinab, A. Modelling organisational factors influencing sustainable development implementation performance in higher education institutions: An interpretative structural modelling (ISM) approach. Sustainability 2019, 11, 4312. [CrossRef]

47. Blanco-Portela, N.; R-Pertierra, L.; Benayas, J.; Lozano, R. Sustainability leaders' perceptions on the drivers for and the barriers to the integration of sustainability in Latin American Higher Education Institutions. Sustainability 2018, 10, 2954. [CrossRef]

48. Conner, D.; Falkner, A.; Lantieri, N.; McGavisk, B.; McShea, B. Stakeholder Perceptions of Campus Sustainability Efforts: Lessons from Vermont. Sustainability 2018, 10, 3849. [CrossRef]

49. Farinha, C.S.; Azeiteiro, U.; Caeiro, S.S. Education for sustainable development in Portuguese universities: The key actors' opinions. Int. J. Sustain. High. Educ. 2018, 19, 912-941. [CrossRef]

50. Bohunovsky, L.; Radinger-Peer, V.; Penker, M. Alliances of change pushing organizational transformation towards sustainability across 13 universities. Sustainability 2020, 12, 2853. [CrossRef]

51. Lambrechts, W.; Verhulst, E.; Rymenams, S. Professional development of sustainability competences in higher education: The role of empowerment. Int. J. Sustain. High. Educ. 2017, 18, 697-714. [CrossRef]

52. Lee, K.-H.; Barker, M.; Mouasher, A. Is it even espoused? An exploratory study of commitment to sustainability as evidenced in vision, mission, and graduate attribute statements in Australian universities. J. Clean. Prod. 2013, 48, 20-28. [CrossRef]

53. Ribeiro, M.M.; Hoover, E.; Burford, G.; Buchebner, J.; Lindenthal, T. Values as a bridge between sustainability and institutional assessment: A case study from BOKU University. Int. J. Sustain. High. Educ. 2016, 17, 40-53. [CrossRef]

54. Pollock, N.; Horn, E.; Costanza, R.; Sayre, M. Envisioning helps promote sustainability in academia: A case study at the University of Vermont. Int. J. Sustain. High. Educ. 2009, 10, 343-353. [CrossRef]

55. Hugé, J.; Mac-Lean, C.; Vargas, L. Maturation of sustainability in engineering faculties-From emerging issue to strategy? J. Clean. Prod. 2018, 172, 4277-4285. [CrossRef]

56. Leal Filho, W.; Brandli, L.L.; Becker, D.; Skanavis, C.; Kounani, A.; Sardi, C.; Papaioannidou, D.; Paço, A.; Azeiteiro, U.; de Sousa, L.O.; et al. Sustainable development policies as indicators and pre-conditions for sustainability efforts at universities: Fact or fiction? Int. J. Sustain. High. Educ. 2018, 19, 85-113. [CrossRef]

57. Leal Filho, W.; Will, M.; Salvia, A.L.; Adomssent, M.; Grahl, A.; Spira, F. The role of green and Sustainability Offices in fostering sustainability efforts at higher education institutions. J. Clean. Prod. 2019, 232, 1394-1401. [CrossRef]

58. Hancock, L.; Nuttman, S. Engaging higher education institutions in the challenge of sustainability: Sustainable transport as a catalyst for action. J. Clean. Prod. 2014, 62, 62-71. [CrossRef]

59. Disterheft, A.; Ferreira Da Silva Caeiro, S.S.; Ramos, M.R.; De Miranda Azeiteiro, U.M. Environmental Management Systems (EMS) implementation processes and practices in European higher education institutions-Top-down versus participatory approaches. J. Clean. Prod. 2012, 31, 80-90. [CrossRef]

60. Arroyo, P. A new taxonomy for examining the multi-role of campus sustainability assessments in organizational change. J. Clean. Prod. 2017, 140, 1763-1774. [CrossRef]

61. Ceulemans, K.; Lozano, R.; Alonso-Almeida, M.M. Sustainability reporting in higher education: Interconnecting the reporting process and organisational change management for sustainability. Sustainability 2015, 7, 8881. [CrossRef]

62. Lambrechts, W. The contribution of sustainability assessment to policy development in higher education. Assess. Eval. High. Educ. 2015, 40, 801-816. [CrossRef]

63. Bien, C.; Sassen, R. Sensemaking of a sustainability transition by higher education institution leaders. J. Clean. Prod. 2020, 256. [CrossRef]

64. Lélé, S.M. Sustainable development: A critical review. World Dev. 1991, 19, 607-621. [CrossRef] 
65. Schopp, K.; Bornemann, M.; Potthast, T. The whole-institution approach at the University of Tubingen: Sustainable development set in practice. Sustainability 2020, 12, 861. [CrossRef]

66. Sylvestre, P.; Wright, T.; Sherren, K. Exploring Faculty Conceptualizations of Sustainability in Higher Education: Cultural Barriers to Organizational Change and Potential Resolutions. J. Educ. Sustain. Dev. 2013, 7, 223-244. [CrossRef]

67. Niedlich, S.; Kummer, B.; Bauer, M.; Rieckmann, M.; Bormann, I. Cultures of sustainability governance in higher education institutions: A multi-case study of dimensions and implications. High. Educ. Q. 2020, 74, 373-390. [CrossRef]

68. Avissar, I.; Alkaher, I.; Gan, D. The role of distributed leadership in mainstreaming environmental sustainability into campus life in an Israeli teaching college: A case study. Int. J. Sustain. High. Educ. 2018, 19, 518-546. [CrossRef]

69. Leal Filho, W.; Skanavis, C.; Kounani, A.; Brandli, L.L.; Shiel, C.; do Paço, A.; Pace, P.; Mifsud, M.; Beynaghi, A.; Price, E.; et al. The role of planning in implementing sustainable development in a higher education context. J. Clean. Prod. 2019, 235, 678-687. [CrossRef]

70. Dyball, M.C.; Wang, A.F.; Wright, S. (Dis)engaging with sustainability: Evidence from an Australian business faculty. Account. Audit. Acc. J. 2015, 28, 69-101. [CrossRef]

71. Menon, S.; Suresh, M. Synergizing education, research, campus operations, and community engagements towards sustainability in higher education: A literature review. Int. J. Sustain. High. Educ. 2020, 21, 1015-1051. [CrossRef]

72. Wals, A.E.J.; Blewitt, J. Third-wave sustainability in Higher Education: Some (Inter)national Trends and Developments. In Sustainability Education: Perspectives and Practice Across Higher Education; Selby, D., Sterling, S., Eds.; Taylor \& Francis Group: London, UK, 2010; pp. 55-74.

73. Meadows, D. Leverage Points-Places to intervene in a System. Whole Earth 1997, 91, 78-84.

74. Lewin, K. Group decisions and social change. In Readings in Social Psychology; Newcomb, T.N., Hartley, E.N., Eds.; Holt, Rinehart \& Winston: New York, NY, USA, 1947; pp. 459-473.

75. Rosenbaum, D.; More, E.; Steane, P. Planned organisational change management: Forward to the past? An exploratory literature review. J. Organ. Chang. Manag. 2018, 31, 286-303. [CrossRef]

76. Yáñez, S.; Uruburu, Á.; Moreno, A.; Lumbreras, J. The sustainability report as an essential tool for the holistic and strategic vision of higher education institutions. J. Clean. Prod. 2019, 207, 57-66. [CrossRef]

77. Times Higher Education Impact Rankings. 2021. Available online: https://www.timeshighereducation.com/impactrankings\#!/ page/0/length/25/sort_by/rank/sort_order/asc/cols/undefined (accessed on 12 May 2021).

78. Lozano, R. Are companies planning their organisational changes for corporate sustainability? An analysis of three case studies on resistance to change and their strategies to overcome it. Corp. Soc. Responsib. Environ. Manag. 2013, 20, 275-295. [CrossRef]

79. Ralph, M.; Stubbs, W. Integrating environmental sustainability into universities. High. Educ. 2013, 67, 71-90. [CrossRef]

80. Wals, A.E.J. Sustainability in higher education in the context of the un DESD: A review of learning and institutionalization processes. J. Clean. Prod. 2014, 62, 8-15. [CrossRef]

81. Hamel, E. The dominance of English in the international scientific periodical literature and the future of language use in science. AILA Rev. 2007, 20, 53-71. [CrossRef]

82. Agostino, D.; Dal Molin, M. A grid approach to managing sustainability: Evidence from a multiple Italian case study. Int. J. Sustain. High. Educ. 2016, 17, 875-894. [CrossRef]

83. Aleixo, A.M.; Leal, S.; Azeiteiro, U.M. Conceptualization of sustainable higher education institutions, roles, barriers, and challenges for sustainability: An exploratory study in Portugal. J. Clean. Prod. 2018, 172, 1664-1673. [CrossRef]

84. Baker-Shelley, A.; Van Zeijl-Rozema, A.; Martens, P. Pathways of organisational transformation for sustainability: A university case-study synthesis presenting competencies for systemic change \& rubrics of transformation. Int. J. Sustain. Dev. World Ecol. 2020, 27, 687-708. [CrossRef]

85. Leal Filho, W.; Wu, Y.C.J.; Brandli, L.L.; Avila, L.V.; Azeiteiro, U.M.; Caeiro, S.; Madruga, L.R. Identifying and overcoming obstacles to the implementation of sustainable development at universities. J. Integr. Environ. Sci. 2017, 14, 93-108. [CrossRef]

86. Mahmud, S.N.D.; Nasri, N.M.; Abdullah, S.I.S.S. A whole-of-university approach towards sustainability in a research institute: A force-field analysis. Int. J. Innov. Creat. Chang. 2019, 7, 120-134. 